\title{
Professional Students from Different Areas in relation to depression
}

\author{
Darshana dahiya, Dr. Rajbir Singh. \\ Asst. Prpfessor in Physical education Kanya Mahavidyalaya Kharkhoda Sonipat Haryana. Under Guidance
}

\begin{abstract}
:
Background: The purpose of the study was to assess and compare depression among professional students from different areas.

Methods: For the purpose of the study, 150 professional students from different areas (50 B.C.A Students, 50 Engineering Students \& 50 Physical Education Students) were selected randomly on the basis of stratified random sampling. The subjects were selected from M.D.Univerity Rohtak. The age level of the subjects ranged from 18 to 25 years. Keeping the feasibility criterion in mind, the depression variable was selected for the present study. Depression was assessed with the help of Goldberg Depression Questionnaire (GDQ) constructed and standardized by Ivan Goldberg.

To assess and Compare the level of depression among professional students from different areas, Descriptive Statistics i.e. (Mean, Standard Deviation) and Analysis of Variance (ANOVA) were used. The level of significance was set at 0.05 level.

Conclusion: Significant difference was found among B.C.A Students, Engineering Students and Physical Education Students in relation to Depression. Physical Education Students possessed greater/higher Depression in comparison to B.C.A Students, and Engineering Students. In case of Depression significant difference was found B.C.A Students and Engineering Students; B.C.A Students and Physical Education Students; Engineering Students and Physical Education Students and the observed sequence of performance was found Physical Education Students > B.C.A Students > Engineering Students in relation to Depression.
\end{abstract}

\section{Introduction}

Everyone occasionally feels blue or sad, but these feelings are usually fleeting and pass within a couple of days. When a person has a depressive disorder, it interferes with daily life, normal functioning, and causes pain for both the person with the disorder and those who care about him or her. Depression is a common but serious illness, and most experience that it needs treatment to get better.

Many people with a depressive illness never seek treatment. But the vast majority, even those with the most severe depression, can get better with treatment. Intensive research into the illness has resulted in the development of medications, psychotherapies, and other methods to treat people with this disabling disorder (Depression national institute of mental health. n.d.).

Depression is the psychiatric disability of our time. During the past decade there has been a sharp rise in depression around the world. According to a recent report from the World Health Organization the leading global cause of disability in 1990 was unipolar major depression. In the United States more people are hospitalized for depression than for any other psychiatric condition (Murray, C. \& Lopez, A. n.d.).

In our society's zeal to find simple solutions to complex problems, depression was defined primarily as a biochemical disease to be treated medically. Thus this complex condition with all its emotional, psychological, cultural, and biological elements was disconnected from life events and human circumstances and reduced to a genetic defect.

Depressive symptoms were viewed as the result of unconscious conflicts with the transference relationship a key feature in treatment. The most recent development in the Freudian approach is a time-limited psychodynamic therapy published in a training manual based on changing personality and character structure (Strupp, H. H. \& Binder, J. C. 1984).

The history of depressive disorders is described in detail by Jackson. The experience of depression has plagued humans since the earliest documentation of human experience. Ancient Greek descriptions of depression referred to a syndrome of melancholia, which translated from the Greek means black bile. In humoral theory, black bile was considered an etiologic factor in melancholia. This Greek tradition referred to melancholic temperament which is comparable to our understanding of early onset dysthymic conditions or depressive personality. During the late 19th and early 20th centuries, phenomenologist increasingly used the term depression or mental depression to refer to the clinical syndrome of melancholia (Jackson, S. W. 1986). 


\section{Objectives of the Study}

1. To assess depression among professional students from different areas.

2. To compare depression among professional students from different areas.

\section{Hypothesis}

It was hypothesized that there will not be any significant difference among professional students in relation to depression.

\section{Selection of Subjects}

\section{Procedure And Methodology}

For the purpose of the study, 150 professional students from different areas (50 B.C.A Students, 50 Engineering Students \& 50 Physical Education Students) were selected randomly on the basis of stratified random sampling. The subjects were selected from M.D. University Rohtak. The age level of the subjects ranged from 18 to 25 years.

\section{Selection of Variables}

Keeping the feasibility criterion in mind, the depression variable was selected for the present study.

\section{Criterion Measures}

Depression was assessed with the help of Goldberg Depression Questionnaire (GDQ) constructed and standardized by Ivan Goldberg.

\section{Statistical Analysis}

1. To assess the level of depression among professional students from different areas, Descriptive Statistics i.e. (Mean, Standard Deviation) was used.

2. To compare the depression among professional students from different areas, Analysis of Variance (ANOVA) was used.

3. The level of significance was set at 0.05 level.

\section{Findings Of The Study}

The findings pertaining to descriptive statistics, one way analysis of variance (ANOVA) as well as post hoc test for the depression variable of one hundred and fifty Professional Students from different areas have been presented in table no. 1 to 3 .

Table-1Descriptive Statistics of Professional Students from Different Areas in relation to Depression

\begin{tabular}{|l|l|l|l|l|l|}
\hline B.C.A. Students & Engineering Students & \multicolumn{2}{l|}{ Physical Education Students } \\
\hline Mean & 15.7400 & Mean & 12.4400 & Mean & 19.2600 \\
\hline Standard Error & 1.73342 & Standard Error & 1.40761 & Standard Error & 1.72161 \\
\hline Median & 11.5000 & Median & 9.5000 & Median & 16.5000 \\
\hline Standard Deviation & 12.25713 & Standard Deviation & 9.95328 & Standard Deviation & 12.17359 \\
\hline Sample Variance & 150.237 & Sample Variance & 99.068 & Sample Variance & 148.196 \\
\hline Kurtosis & 4.986 & Kurtosis & .860 & Kurtosis & .105 \\
\hline Skewness & 1.923 & Skewness & 1.066 & Skewness & .750 \\
\hline Range & 62.00 & Range & 43.00 & Range & 49.00 \\
\hline Minimum & .00 & Minimum & .00 & Minimum & 1.00 \\
\hline Maximum & 62.00 & Maximum & 43.00 & Maximum & 50.00 \\
\hline Count & 50 & Count & 50 & Count & 50 \\
\hline
\end{tabular}

It is evident from table - 1 that mean and standard deviation scores of B.C.A. Students, Engineering Students and Physical Education Students in relation to Depression has been found 15.74, 12.44 \& 19.26 and $12.25,9.95 \& 12.17$ respectively and range of score was $62,43 \& 49$ respectively where as standard error was found $1.73,1.40 \& 1.72$ respectively.

Table-2_Analysis of Variance of Professional Students from Different Areas in relation to Depression

\begin{tabular}{|l|l|l|l|l|l|}
\hline Source of Variation & $\begin{array}{l}\text { Sum of of } \\
\text { Squares }\end{array}$ & Df & Mean Square & F-Value & Sig. \\
\hline Between Groups & 1163.213 & 2 & 581.607 & $4.389^{*}$ & .014 \\
\cline { 1 - 4 } Within Groups & 19477.560 & 147 & 132.500 & & \\
\hline
\end{tabular}

* Significant at 0.05 level of significance

F $0.05(2,147)=3.06$

Table- 2 revealed that there was significant difference among B.C.A. Students, Engineering Students and Physical Education Students in relation to Depression, as obtained F-ratio was 4.38, which was higher than the tabulated value of 3.06 , required for F-ratio to be significant at 0.05 level with $(2,147)$ degree of freedom. 
Since the one way analysis of variance was found significant in relation to Depression, the least significant difference (LSD) test was applied to find out the differences of the paired means among B.C.A. Students, Engineering Students and Physical Education Students.

Table-3 Least Significant Difference (LSD) post hoc test for the paired means among B.C.A. Students, Engineering Students and Physical Education Students in relation to Depression

\begin{tabular}{|l|l|l|l|l|l|}
\hline Means & E.C.A. Students & $\begin{array}{l}\text { Engineering } \\
\text { Students }\end{array}$ & $\begin{array}{l}\text { Physical Education } \\
\text { Students }\end{array}$ & Sig. & Mean Difference \\
\hline 15.7400 & 12.4400 & & .154 & $3.30000^{*}$ \\
\hline 15.7400 & & 19.2600 & .128 & $3.52000^{*}$ \\
\hline & 12.4400 & 19.2600 & .004 & $6.82000^{*}$ & 0.860 \\
\hline
\end{tabular}

* Significant at 0.05 level of significance

It is evident from table- 3 that paired mean differences among B.C.A Students, Engineering Students and Physical Education Students in relation to Depression was found significant between B.C.A. Students and Engineering Students; B.C.A. Students and Physical Education Students; Engineering Students and Physical Education Students.

The graphical representation of means among B.C.A. Students, Engineering Students and Physical Education Students in relation to Depression has been presented in figure No.3.

\section{Figure 1 Graphical representation of the Comparison of Means of Professional Students from Different Areas in relation to Depression}

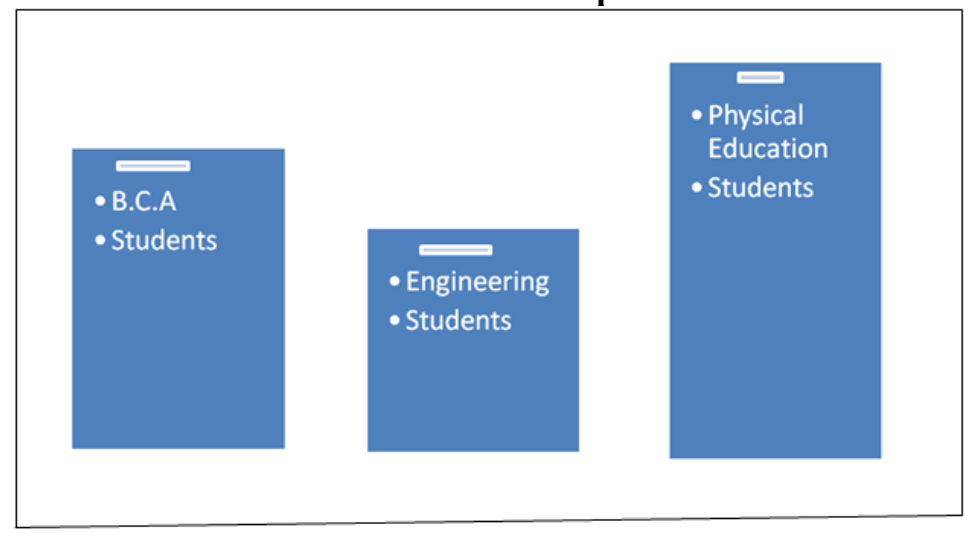

\section{Discussion and Finding}

The findings of the study revealed that the significant difference was found among B.C.A. Students, Engineering Students and Physical Education Students in relation to Depression whereas Physical Education Students possessed greater/higher Depression in comparison to B.C.A. Students, and Engineering Students. The findings may be attributed to the fact that the Depression generally refers to the mental state of excessive sadness characterized by persistently low mood, loss pleasure and interest. Probably the higher score of Depression could be attributed to the Sportsmen which were chosen for the study has already achieved their highest level of achievement. They are worried about their carrier prospectus probably uncertainty in choosing a carrier might have inculcated the feeling of failure moreover they might have the feeling that Sports participation has not contributed to their carrier therefore they have score higher in Depression whereas B.C.A. and Engineering Students (Non-Sports Persons) have clear path or carrier option with regard to their profession. Hence may feel more secure professionally.

Further, In case of Depression significant difference was found between B.C.A. Students and Engineering Students; B.C.A. Students and Physical Education Students; Engineering Students and Physical Education Students and the observed sequence of performance was found Physical Education Students $>$ B.C.A. Students $>$ Engineering Students in relation to Depression. The reason for this may be that Physical Education Students are anxious about their future career prospects and grades during course which leads to tendency of Depression in them in comparison to B.C.A. Students and Engineering Students.

\section{Discussion of Hypothesis}

The hypothesis, that there will not be any significant difference among professional students in relation to Depression is rejected since significant difference was found among professional students in relation to Depression. 


\section{Conclusions}

1. Significant difference was found among B.C.A. Students, Engineering Students and Physical Education Students in relation to Depression.

2. Physical Education Students possessed greater/higher Depression in comparison to Medical Students, and Engineering Students.

3. In case of Depression significant difference was found between B.C.A. Students and Engineering Students; BCA Students and Physical Education Students; Engineering Students and Physical Education Students and the observed sequence of performance was found Physical Education Students $>$ BCA Students $>$ Engineering Students in relation to Depression.

\section{References}

[1]. Ingram, R. E., Miranda, J. \& Segal, Z. V. (1998). Cognitive Vulnerability to Depression. New York: Guilford Press.

[2]. Jackson, S. W. (1986). Melancholia and Depression. New Haven: Yale University Press.

[3]. Seligman, M. E. P., Walker, E .F. \& Rosenhan, D. L. (1982). Abnormal Psychology. New York: W.W. Norton \& Company, Inc.

[4]. Strupp, H. H. \& Binder, J. C. (1984). Psychotherapy in a New Key: A Guide to Time-Limited Dynamic Psychotherapy. New York: Basic Books.

[5]. Andrews B., Hejdenberg J. and Wilding J. (2009) "Student anxiety and depression: Comparison of questionnaire and interview assessments"

Journal of Affective Disorders, Volume 95, Issue 1, Pages 29-34.

[6]. Babiss, M. S. \& Gangwisch, J. E. (2009). Sports Participation as a Protective Factor against Depression and Suicidal Ideation in Adolescents as Mediated by Self-Esteem and Social Support. Journal of Developmental \& Behavioral Pediatrics, 30(5). 376-384.

[7]. Bayram Nuran and Bilgel Nazan (2008) "The prevalence and socio-demographic correlations of depression, anxiety and stress among a group of university students" Social Psychiatry and Psychiatric Epidemiology, Volume 43, Number 8, pages 667-672.

[8]. Beekman, A. T., De, B. E., Van, B. A., Deeg, D. J., Van-Dyck, R. \& Van, T. W. (2000). Anxiety and Depression in Later Life: CoOccurrence and Communality of Risk Factors. Journal of American Psychiatric Association, 157(8), 89-95. 